\title{
Teachers' Perception for Integrating Educational Robots and Use as Teaching Assistants in Thai Primary Schools
}

\author{
Kajornpong Poolsawad ${ }^{1}$, Noawanit Songkram ${ }^{1,2 *}$, Krerk Piromsopa ${ }^{3}$, \\ Nutthakorn Songkram ${ }^{4}$ \\ ${ }^{1}$ Department of Education Technology and Communications, Faculty of Education, Chulalongkorn University, Bangkok, Thailand \\ ${ }^{2}$ Learning Innovation for Thai Society (LIfTS) Research Unit, Chulalongkorn University, Bangkok, Thailand \\ ${ }^{3}$ Department of Computer Engineering, Faculty of Engineering, Chulalongkorn University, Bangkok, Thailand \\ ${ }^{4}$ Department of Innovative Communication and Agricultural Development, Faculty of Agricultural Technology, King Mongkut's Institute \\ of Technology Lakrabang, Bangkok, Thailand
}

\begin{abstract}
This study focused on teachers' perception for integrating educational robots into learning and the feedback of teachers and students who used an education robot prototype as a part of learning. Data were collected from 510 primary school teachers who were used in a confirmatory analysis of factor model. Confirmatory Factor Analysis (CFA) indicated a good fit with a six-factor model in the observed data, which could be presented through six dimensions of robotic education quality, including social interaction, cognitive function, teaching method, learner characteristics, main features, and content. The prototype-testing phase was carried out using 5th grade students at a primary school in Thailand. The robot was tested for 10 hours, which included 20 students participating in the focus group. The research results showed that integrating the six dimensions of robotic education into the educational robot prototype resulted in a strong positive improvement in the focus groups learners' behavior and supported the instructors during the learning process. In contrast, some teachers lacked experience and confidence with robots integrated with LMS, which caused challenging obstacles in teaching. The results were achieved when integrating the six-factor model into education robots to improve student learning. Future researchers should expand their studies to look into the opportunities and challenges that teachers and school administrators face in the classroom.
\end{abstract}

\section{Keywords:}

Education Robots;

Learning Management System (LMS);

Teaching Method;

Emotional Engagement;

Learners' Behavior.

\section{Article History:}

Received: 29 August 2021

Revised: 21 October 2021

Accepted: 03 November 2021

Published: 16 November 2021

\section{1- Introduction}

Technology is currently developing rapidly, meaning that children now grow up with digital appliances and various technologies from a young age, which has a significant influence on society, culture, and learning. In particular, $71 \%$ of learners aged 15-24 use the internet daily [1]. These learners' skills and willingness to use technology has resulted in education institutes increasing their use of technology in the classroom. Moreover, robots are highly important modern technology, and their use is expected to increase [2,3]. Education research into the use of robots in the United States has focused largely on STEM learning (Science, Technology, Engineering, and Mathematics) [4]. These robots have been utilized to develop problem-solving skills and build comprehension of science and technology among primary school students.

*CONTACT: noawanit.so@gmail.com; noawanit.s@chula.ac.th

DOI: http://dx.doi.org/10.28991/esj-2021-SP1-09

(C) 2020 by the authors. Licensee ESJ, Italy. This is an open access article under the terms and conditions of the Creative Commons Attribution (CC-BY) license (https://creativecommons.org/licenses/by/4.0/). 
Many studies have also used educational robots as class aids to enhance learning. Educational robots have been used to support in-class learning activities to stimulate learners to respond and interact with lessons [5, 6]. In addition, education robots have been used as a tool to inspire and support learning as well as in building learning experiences [7]. They have also been used to enhance learning, such as by using teaching assistant robots to teach learners of English as a second language (ESL) in primary school, or using teaching assistant robots to improve English as a foreign language students' understanding of science. The research found that the average pre-learning scores were lower than the post learning scores, with the students scoring $26.9 \%$ and $42.3 \%$, respectively. Meanwhile, combining the teaching assistant robot with gamified teaching or gamification robots enhanced interaction between the lessons and learners as well as motivated their learning because the teaching assistant robots brought joyfulness, excitement, interaction, and made the learning engaging [8]. Chang et al. (2010) [8] separated the results into the use of robots for STEM, robots to act as teaching support, and teaching assistant robots to support learning by games.

Presently, educational robots designed with gamification in combination with lessons for language and brain development are of interest since such robots can enhance student engagement by attracting their attention [9]. However, it has been found that the gamification robot cost remains high, such as NAO and LEGO Mindstorms, which instructors could not use widely [10]. The problem of interface design was difficult to use and content and activities design was not appropriate with learners either. Instructors are therefore not able to use robots to help with teaching in schools in a broad manner [11]. In the present study, the researcher developed a gamification robot combined with online lessons to support learner achievement and engagement by developing cheap and effective robots and organizing new teaching and learning trends to enhance engagement through gamification. Teaching and learning by gamification can be described in two ways. First, it can involve building games for non-entertainment contexts or learning purposes, or second, it could involve converting existing lessons into game forms [12].

Previous studies have developed and integrated gamification for educational robots with instruction methods [13, 14]. Meanwhile, the use of robots has been found to affect skills development and problem solving with gamification among students [15], in addition to enhanced motivation, participation engagement, and interest [16]. Furthermore, learners' intention to learn, lesson comprehension, knowledge learning, skills, academic expertise, and engagement have improved through effective teaching and learning. Student engagement with their learning also affects their learning achievement. Participation and engagement involves integration between verbal and non-verbal activities, while gestures and facial expression are communication forms that support participation and engagement [17]. Teaching games have been proposed to stimulate participation and engagement, learners' attention, competitiveness, and through teachings, attitudes, and various skills, which have be found to contribute to learning. When games are developed and used in class, important factors include the nature, the role of the academic game, score criteria, and winning. Crucially, the designer must create a suitable design for gamified teaching in class.

An education robot was developed to enhance learners' participation and engagement with lessons, in part due to the robot being shaped like a toy and its ability to interact in an excited manner, which enhanced learner attention. The following research questions arise from the basis of the present study:

- How do teachers envision integrating educational robots into learning?

- What feedback did the teachers and students face as they used the education robot prototype as a part of learning?

This study is organized as follows: Section 2 proceeds with a critical factors literature review and presents the factors to maximize the design of educational robots as teaching assistants in Thailand. Section 3 describes the methodology, the quantitative and qualitative data collected for this mixed-methods research, and the research process in detail. Section 4 begins by presenting the analytical results for the construct validity utilized confirmatory factor analysis (CFA) to check the suitability and correction of the structural equation modelling and how data were collected and organized. Section 5 discusses the results and shows how education robots interacted with learners' feedback and improved student engagement. Finally, Section 6 presents the successes and challenges and answers the research questions.

\section{2- Literature Review}

Educational robots are a type of social robot that have been developed to enhance learners' participation and engagement with lessons. Many studies have reported the advantages of gamification for educational robots. However, few studies have reported the problem of gamification for educational robots facets of confirmatory factor analysis of quality factors to maximize the design of educational robots as teaching assistants in Thailand. To analyze the selected articles, we focused on systematic reviews and synthesized the findings over the past fifteen years to assess the influence of educational robots on children in the learning context. Six major factors were examined including (1) Social interaction, (2) Cognitive function, (3) Teaching method, (4) Learner characteristics, (5) Main features, and (6) Content. 


\section{2-1- Social Interaction}

Actions or ideas transfer between individuals or groups of people with a teaching assistant robot educational and motivate children. Thus, the value of integrating children's learning comes from their social and emotional development.

In this study, actions or ideas transferred between individuals or groups of people with a teaching robot serve to educate and motivate children, meaning that the value of integrating children's learning comes from their social emotional development [18]. Integrating childhood education is derived from children's social development and their emotions from learning together. It is broadly accepted that robots can aid students' communication and ability to respond to others [19] by fostering participation and interaction between learners and educational robots [20, 21]. Previous results suggest that educational robots enhance the development of student abilities to participate in new activities and engage intellectual skills [22], creating good emotional relations, and responding to social needs. The result is the interaction that is more effective since they have the skills to understand others [23]. This supports good emotional relations and can increase the acceptance of social members. Therefore, robots can interact with humans in a friendly way and understand human emotions, in addition to expressing emotions through facial expressions, voice, gestures, and body movements in accordance with the conversation context [24]. Another study suggests that robots' sympathetic expressions affect children's positive sense [22], and most students responded that their main motivation was friendship with the robot [26]. Users of social robots must feel safe and comfortable, and the robot should match the user's personality. Additionally, robots capable of understanding user's feelings and emotions affected their attitude. A suitable emotional response to users was therefore important for the user's confidence and satisfaction, including acting upon the user's command. Robots involved in social interaction should perceive the user's social behavior and respond to their touch, and likewise be able to interpret and avoid obstacles. Thus, AI features are used in robots to facilitate interactions between humans and robots.

\section{2-2- Cognitive Function}

Cognitive function means that learners seek knowledge and learn new information [26]. Studies on the components of robotics for education have found that children have different learning potential that often depend upon their learning experience based on comprehension of the lesson, as well as their interpretation, understanding, and application of using robots [27]. In designing robot/student interactions, the robot must be able to evaluate a student's learning through a pretest and post-test [28]. Furthermore, Eklundh, Kerstin, Anders Green, and Helge Hüttenrauch [29] discussed students' reflection to build interaction with educational robots, which could be useful for future robot design.

\section{2-3- Teaching Method}

In this study, teaching method refers to the content, teaching technique design, and learning procedure guidance to achieve learning targets [30]. The aim was to develop the learning and teaching design in schools integrated with educational robots [31]. Robots used as teaching aids affect student learning by developing their self-knowledge and self-test knowledge. From the study, educational robots were found to be suitable for the STEM (science, technology, engineering, and math) education curriculum in primary and secondary schools [6, 32]. Furthermore, McLurkin, Rykowski, John, Kaseman, and Lynch [33] evaluated the impact of educational robots in STEM education, and found their use to be effective, cheap and durable for education methods. Altin and Pedaste [31] concluded that the most popular methods were problem-based learning, constructivist, and competition-based learning. Moreover, other methods included discovery learning, communication-based learning, and project-based learning. Nag, Katz, and Saenz-Otero [34] support the use of robots in problem-based learning, which affects students' skills development in mathematics, physics, strategic planning, and meaningful communication. However, Altin and Pedaste [31] debated whether there might be a lack of evidence showing that STEM educational robots helped with discovery, learning, collaborative learning, problem solving, project-based learning, competition-based learning, compulsory learning, and meeting target achievements. Therefore, additional research is required to examine how teaching aids can be adjusted when using robots [35], while teachers must receive training on how robots can be used in the classroom [13].

\section{2-4- Learner Characteristics}

Learner characteristics refer to the age and sex of the learners' specific characteristics, such as learning interest. UTAUT (Unified Theory of Acceptance and Use of Technology) is used to evaluate robot technology acceptance [36]. The following elements have been identified as directly influencing technology acceptance: Expectation of effectiveness, expectation of ease of use, and social influence [36]. Age, sex, and voluntary use were used as control variables for technology acceptance.

\section{2-5- Main Feature}

The main features required for the robot include robot operation stability and ease of use, as well as other characteristics such as not being a danger to children. Surveys found that many details about the acceptance of using robots [36], with the main qualification of robot being "easy to use," confidence with using a robot, followed by the safety rules and working stability [37]. Additional robot characteristics include being durable for use with children [38]. 


\section{2-6- Content}

It is important that the teacher make a decision about the course content that is most appropriate for the course. At present, technology has developed rapidly and robots are increasingly used in schools [39]. At the same time, the current generations of school-aged children have become used to using modern technology [2]. Meanwhile, studies have found that robots influence children's understanding and development of foreign language skills, social interaction, and ethics $[6,40,41]$ because they stimulate learning interaction and participation in learning activities [5, 6]. Moreover, Mubin, Stevens, Shahid, Al Mahmud, and Dong [42] and Benitti [13] revealed that the TARAL robot could aid student learning of foreign languages, science, and technology. Similarly, other studies found that teaching robots aid primary schools to develop learning interaction and stimulate participation [8, 43]. In addition, they also help students interested in learning a foreign language [5] and telling a story. Barker and Ansorge [44] showed that students' learning achievement improved by using robots in science, while Kazakoff, Sullivan, and Bers [45] found that robots help the learning of how to write operation control programs. Other researchers have suggested that robots are effective at helping the learning of science, engineering, and technology [46, 47].

\section{3- Methodology}

In this study, both quantitative and qualitative data were collected for this mixed-methods research. Qualitative interviews and a quantitative survey were combined to examine the factors relating to teachers' perception on the quality of educational robots.

The order of the methodology steps is as follows (Figure 1):

- A literature review was conducted to explore contextual factors relating to educational robots by selecting systematic reviews.

- Focus group interviews were conducted with professionals to verify and confirm the contextual factors and create a model.

- For sample and data collection, a survey on proposed model questionnaire was created containing 21 questions, which were divided into six factors of (1) social interaction, (2) cognitive function, (3) teaching method, (4) learner characteristics, (5) main features and (6) content. Confirmatory Factor Analysis was carried out using LISREL to examine the structure of the contextual factors (CFA model).

- Prototype development was used as a step to develop a prototype for gamification robot from the gamification theory.

- Prototype testing was conducted on the robot for 10 hours among 20 students at a primary school.

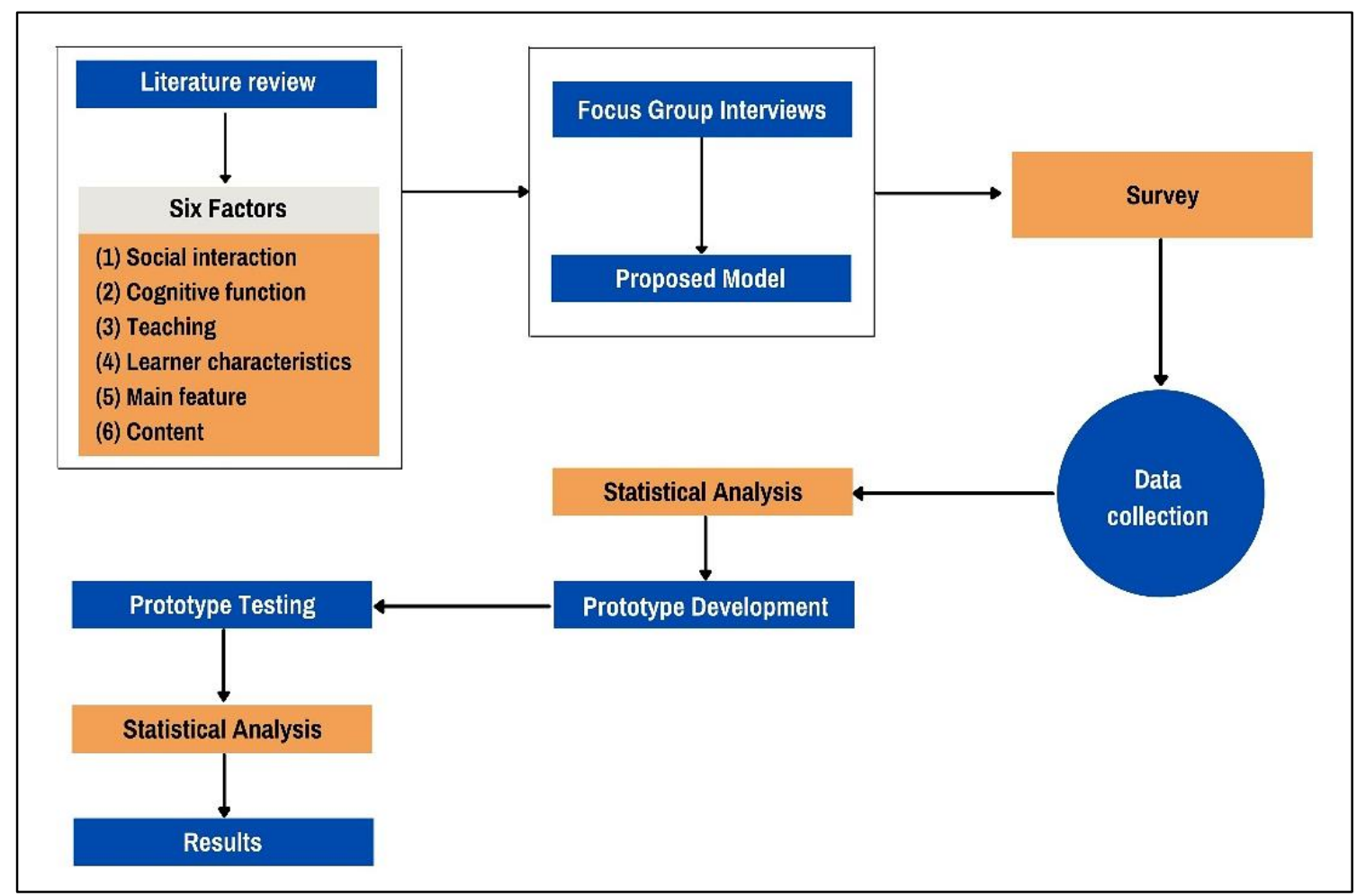

Figure 1. Research methodology steps. 


\section{3-1- Sample and Data Collection}

Survey data was collected from primary school teachers after developing the 21 questions based on the six related literature reviews: (1) Social interaction, (2) Cognitive function, (3) Teaching aid, (4) Learner characteristics, (5) Main feature, and (6) Content.

Data were collected from 19 schools by multi-stage sampling, which were categorized separated by school size, (small, medium, and large) from all schools in Thailand. The data collected from school instructors could then be then separated into 255 public school sets and 255 private school sets.

Data were collected from 510 primary school teachers, of which $78.6 \%$ were female and $21.4 \%$ male, while $34.9 \%$ were aged between $21-30$ years and $29.41 \%$ were aged between $31-40$ years. From the sample, $31.6 \%$ had over 10 years of work experience. The sample group of teachers taught Thai (15.5\%), Mathematics (14.5\%), English (11.6\%), and Society $(10.2 \%$ ) (see Table 1). The sample group included teachers of Prathomsuksa 1 - Prathomsuksa 6 (Primary school first to sixth grades) at similar percentages (see Table 2).

Table 1. Teaching sampling group by subject $(\mathrm{N}=510)$.

\begin{tabular}{ccc}
\hline Sample characteristics & Frequency & Percentage \\
\hline Thai & 79 & 15.5 \\
Mathematics & 74 & 14.5 \\
English & 59 & 11.6 \\
Society & 52 & 10.2 \\
Science & 50 & 9.8 \\
Physical/ Health education & 46 & 9.0 \\
Computer/ Information computer technology & 33 & 6.5 \\
History & 22 & 4.3 \\
Music/ classical dance & 18 & 3.5 \\
Occupation & 17 & 3.3 \\
Art & 16 & 3.1 \\
Chinese language/foreign language & 14 & 2.7 \\
Mathematics/Science & 10 & 2.0 \\
Others & 9 & 1.8 \\
Integration/ Project & 8 & 1.6 \\
Early childhood/learner improvement & 3 & 0.6 \\
\hline
\end{tabular}

Table 2. Class teaching sampling $(\mathrm{N}=\mathbf{5 1 0})$.

\begin{tabular}{ccc}
\hline Sample characteristics & Frequency & Percentage \\
\hline Prathomsuksa 1 ( $1^{\text {st }}$ Grade $)$ & 144 & 28.2 \\
Prathomsuksa 2 ( $2^{\text {nd }}$ Grade $)$ & 138 & 27.1 \\
Prathomsuksa $3\left(3^{\text {rd }}\right.$ Grade $)$ & 155 & 30.4 \\
Prathomsuksa $4\left(4^{\text {th }}\right.$ Grade $)$ & 140 & 27.5 \\
Prathomsuksa 5 ( $5^{\text {th }}$ Grade $)$ & 167 & 32.7 \\
Prathomsuksa $6\left(6^{\text {th }}\right.$ Grade $)$ & 169 & 33.1 \\
\hline
\end{tabular}

Questionnaires were mailed to the sample group. The questionnaires were divided into six sections (Figure 2): (1) Social interaction (Social) of learning aid robot, (2) Cognitive function (Cognitiv) of learners by using learning aid robot, (3) Teaching aid (Teaching) by using learning aid robot, (4) Learner characteristics (Learner), (5) Main feature (Main_fe) of learning aid robot, and (6) Content (Content) of subject for learning aid robot. 


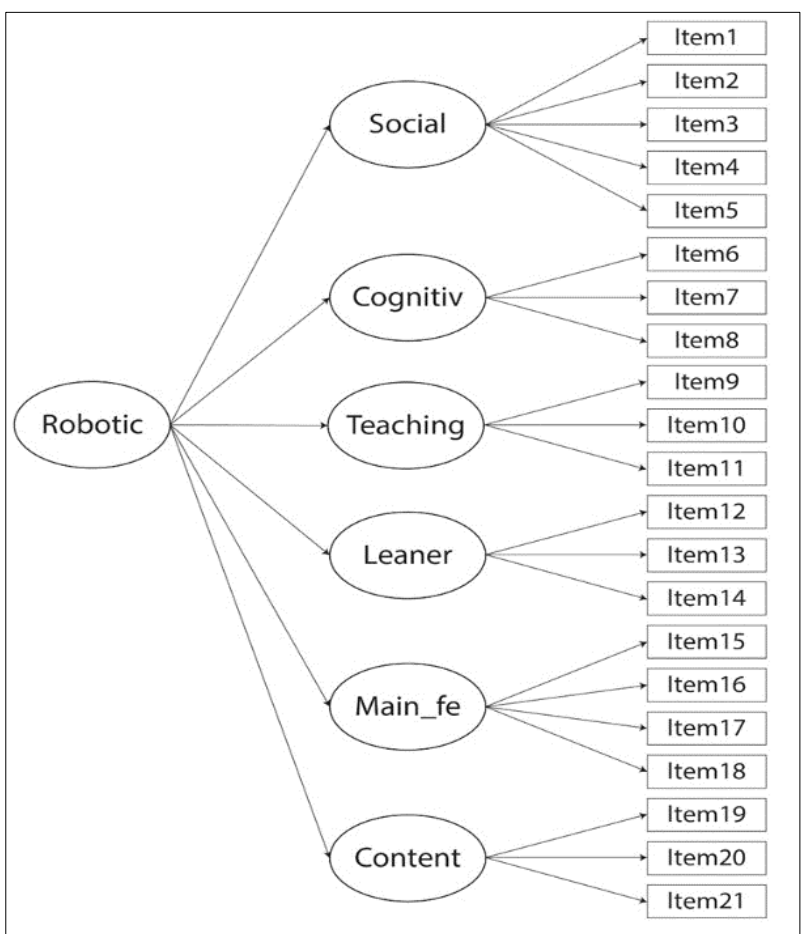

Figure 2. Model structure of the teaching aid robot for primary school learners.

The analytical results of the Correlation matrix by Bartlett's Test of Sphericity Chi-Square ranged from 499.1381218.173, $\mathrm{d}_{\mathrm{f}}$ between 3-10 and $p=0.000$, which was significantly different at 0.01 , showing that the correlation coefficient of the observed variables was not the identity matrix, and that the variables were sufficiently related to be able to analyze the composition. The index value of Kaiser-Mayer-Olkin (KMO) was 0.649-0.845.

\section{4- Analysis and Results}

The analytical results for the construct validity utilized confirmatory factor analysis (CFA) to check the suitability and correction of the structural equation modelling by confirmatory factor loading and $\mathrm{R}^{2}$ check for the variation indicator (Table 4). The analytical results from the perspectives of teachers to help teach in primary schools can be separated into six factors (Table 5): (1) Social interaction, (2) Cognitive function, (3) Teaching, (4) Learner characteristics, (5) Main_Fe, and (6) Content.

\section{4-1- Factor 1 Social Interaction}

The component variables of social interaction had a construct reliability $\left(\rho_{c}\right)$ equal to 0.877 . Considering the observed variables for social interaction factor, it was found that the indicators that had the most important weight for identifying social interaction factor were robot built friendly (item 2), which had a weight value of 0.77 , while the covariance value $\left(\mathrm{R}^{2}\right)$ of the indicator for the social interaction factor equaled $56 \%$. This was followed by the weight of the indicator for robot with artificial intelligence (AI) for sensing, interpretation, and responding (item 5), which equaled 0.73, while the covariance value $\left(\mathrm{R}^{2}\right)$ of the indicator for social interaction factor equaled $64.0 \%$. The least weighted variable of social interaction was likely to be the robot is shaped like an animal or cartoon, which attracts attention (item 4). This variable had a weight value of 0.62 , while the covariance value $\left(\mathrm{R}^{2}\right)$ of the indicator for the social interaction factor equaled $46.0 \%$

\section{4-2- Factor 2 Cognitive Function}

The component variables of cognitive capacity had a construct reliability $\left(\rho_{c}\right)$ equal to 0.889 . Considering the observed variables for cognitive function, it was found that the robot installed with a pre-test program (item 6) had the most important weight in determining the measurement of cognitive capacity (cognitive capacity) with the highest weight variable equal to 0.80 , while the covariance value $\left(\mathrm{R}^{2}\right)$ of the indicator of cognitive function factor equal to $78.0 \%$. The least weighted variable of cognitive function factor was the robot was given recommendations from learners (item 8 ), which had a variable weight equal to 0.76 , while the covariance value $\left(\mathrm{R}^{2}\right)$ of the indicator for cognitive function factor equaled $62.0 \%$.

\section{4-3- Factor 3 Teaching Method}

The component variables of the teaching method had construct reliability $\left(\rho_{c}\right)$ equal to 0.806 . Considering the observed variables for teaching method factor, it was found that the variable with the highest weight of teaching method 
factor indicator was robot cooperated with teaching by problem-based learning (item 10) with the highest weight variable in teaching method factor equal to 0.67 , while the covariance value $\left(\mathrm{R}^{2}\right)$ of the indicator for teaching method factor equaled $62 \%$. The least weighted variable of the teaching method factor was robot aided teaching by project-based learning (item 11), which had a weight of 0.58 , while the covariance value $\left(\mathrm{R}^{2}\right)$ of the indicator for the teaching method factor equaled $53.0 \%$

\section{4-4- Factor 4 Learner Characteristics}

The component variables of learners' characteristics construct reliability $\left(\rho_{c}\right)$ equaled 0.767 . Considering the observed variables for learner characteristics, it was found that the most important indicator was learner attention, which was important to education quality by learning aid robot (item 14) with a weight of 0.77 , which had a weight of 0.58 , while the covariance value $\left(\mathrm{R}^{2}\right)$ of the indicator for the teaching method factor equaled $78.0 \%$. The least weighted variable of the learner sex was important to education quality by learning aid robot (item 13) with a variable weight of 0.48 , while the covariance value $\left(\mathrm{R}^{2}\right)$ of the indicator for the teaching method factor equaled $23.0 \%$.

\section{4-5- Factor 5 Main Feature (Main_fe)}

The component variables of main feature factor has a construct reliability $\left(\rho_{c}\right)$ equal to 0.926 . Considering the observed variables for main feature factor, it was found that the most important was the robot was easy to work with (item 16), with the highest weight variable equal to 0.83 , while the covariance value $\left(\mathrm{R}^{2}\right)$ of the indicator for the cognitive function factor equaled $79.0 \%$. The least weighted variable of the main feature factor was physicality of the robot (item 17) with a variable weight of 0.80 , while the covariance value $\left(R^{2}\right)$ of the indicator for the main feature factor equaled $78.0 \%$.

\section{4-6- Factor 6 Content}

The component variable of content had a construct reliability $\left(\rho_{c}\right)$ equal to 0.918 . Considering the observed variables for content factor, the most important variable was using a robot aid in technology teaching (item 21), which had a weight of 0.79 , while the covariance value $\left(\mathrm{R}^{2}\right)$ equaled $81.0 \%$.

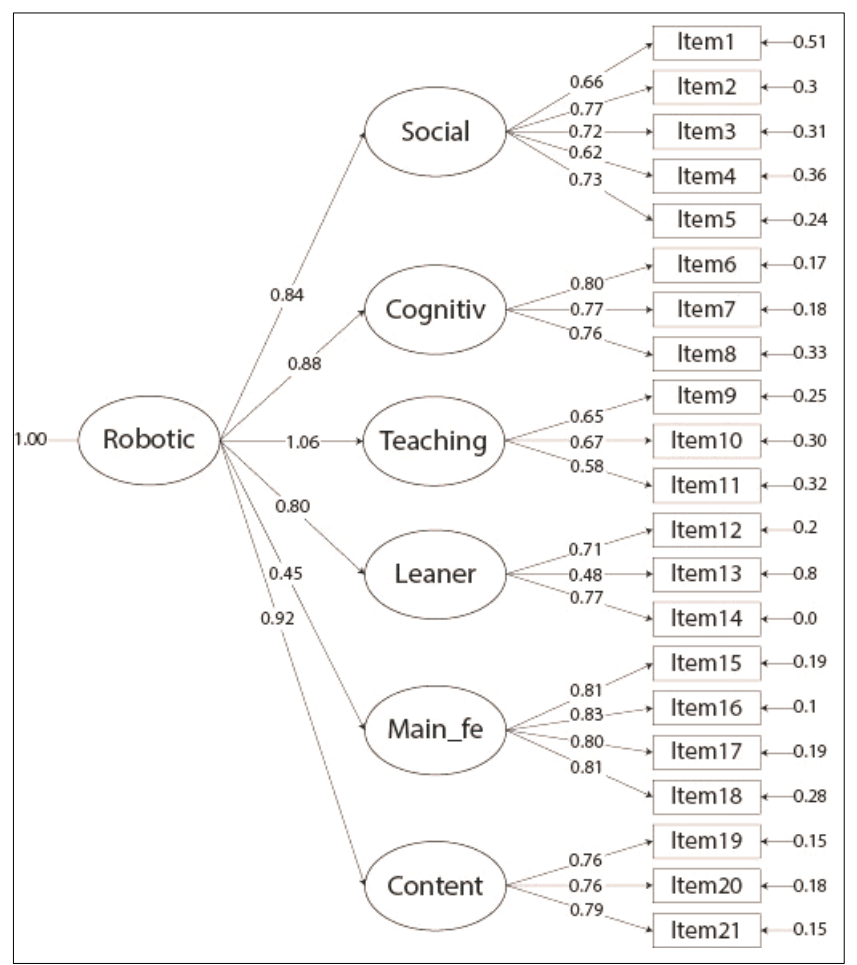

Figure 3. Analysis of the goodness of fit indices in education quality with a learning aid robot.

\section{4-7- SEM Analysis}

SEM analysis was conducted for hypothesis testing by Maximum Likelihood using the LISREL program by considering the statistics used as indicators for six items, namely $\chi^{2}$, CFI, GFI, AGFI, RMSEA, and SRMR (see Table $3)$. In this study, the hypothesized theoretical model showed a good fit with the collected data. The goodness of fit provided evidence that the hypothesized model was stable, in which $(P-$ value $>0.05)$. The best fitting solution is illustrated in Figure 3. All estimated path coefficients were significant. 
Table 3. Fit indices of six components.

\begin{tabular}{cccc}
\hline Fit measure & Criterion & Model Value & Note \\
\hline$\chi^{2} / \mathrm{df}$ & $<2.00$ & 1.296 & Fit \\
CFI & $>0.95$ & 1.000 & Fit \\
GFI & $>0.95$ & 0.970 & Fit \\
AGFI & $>0.90$ & 0.950 & Fit \\
RMSEA & $<0.05$ & 0.024 & Fit \\
SRMR & $<0.05$ & 0.021 & Fit
\end{tabular}

Table 4. Factor loading weight of dimension for the model of education quality by learning aid robot from teachers' perspectives.

\begin{tabular}{ccccccc}
\hline Variables & $\mathbf{B}$ & beta & $\mathbf{S E}$ & $\mathbf{t}$ & $\mathbf{R}^{\mathbf{2}}$ & Factor score coefficient \\
\hline \multicolumn{2}{c}{ Education quality } & by learning aid robot (Robotic_EDQ) \\
\hline Social interaction (Social) & 0.84 & 0.94 & 0.057 & 14.76 & 0.89 & 0.11 \\
Cognitive function (Cognitive) & 0.88 & 0.92 & 0.040 & 21.89 & 0.85 & 0.15 \\
Teaching aid (Teaching) & 1.06 & 1.00 & 0.048 & 22.15 & 1.00 & -0.03 \\
Learners characteristics (Learner) & 0.80 & 0.76 & 0.051 & 15.61 & 0.58 & 0.42 \\
Main feature (Main_fe) & 0.41 & 0.45 & 0.091 & 4.49 & 0.70 & 0.30 \\
Content (Content) & 0.92 & 0.90 & 0.042 & 21.71 & 0.82 & 0.18 \\
\hline
\end{tabular}

Table 5. Summary of factor analysis items and factor loadings.

\begin{tabular}{|c|c|c|c|c|c|c|}
\hline \multirow{2}{*}{ Items } & \multicolumn{6}{|c|}{ Factor Loadings } \\
\hline & 1 & 2 & 3 & 4 & 5 & 6 \\
\hline \multicolumn{7}{|l|}{ Factor 1 Social Interaction } \\
\hline $\begin{array}{l}\text { 1. Robot's emotional expressions stimulated learning (by robot voice, facial expression, } \\
\text { happiness, sadness, amazement, fear, and body movement). }\end{array}$ & 0.66 & & & & & \\
\hline $\begin{array}{l}\text { 2. Robot is friendly with learners (by smiling, greeting, getting along with them, inviting to play } \\
\text { games, telling a story). }\end{array}$ & 0.77 & & & & & \\
\hline 3. Robot stimulated attention (by blinking lights, noise, and touch). & 0.72 & & & & & \\
\hline 4. Robot is shaped like an animal or cartoon, which attracts attention. & 0.62 & & & & & \\
\hline 5. Robot has artificial intelligence (AI) for sensing, interpretation, and responding. & 0.73 & & & & & \\
\hline \multicolumn{7}{|l|}{ Factor 2 Cognitive Function } \\
\hline 6. Robot is installed with a pre-test program. & & 0.80 & & & & \\
\hline 7. Robot is installed with a post-test program. & & 0.77 & & & & \\
\hline 8. Robot was given recommendations from learners. & & 0.76 & & & & \\
\hline \multicolumn{7}{|l|}{ Factor 3 Teaching Method } \\
\hline $\begin{array}{l}\text { 9. Robot cooperated with the teaching method of play-based learning (games and rewards, } \\
\text { levelling up to increase the challenge). }\end{array}$ & & & 0.65 & & & \\
\hline $\begin{array}{l}\text { 10. Robot cooperated with teaching by using problem-based learning (learner-centered teaching } \\
\text { was stimulated by using problems to motivate learners to seek knowledge and solve problems). }\end{array}$ & & & 0.67 & & & \\
\hline $\begin{array}{l}\text { 11. Robot aided teaching by using project-based learning (teaching is student-centered, wherein } \\
\text { students gain deeper knowledge and understanding through self-knowledge and project work). }\end{array}$ & & & 0.58 & & & \\
\hline \multicolumn{7}{|l|}{ Factor 4 Learner Characteristics } \\
\hline 12. Age of learners was important to education quality by learning aid robot. & & & & 0.71 & & \\
\hline 13. Sex of learners was important to education quality by learning aid robot. & & & & 0.48 & & \\
\hline 14. Attention level of learners was important to education quality by learning aid robot. & & & & 0.77 & & \\
\hline \multicolumn{7}{|l|}{ Factor 5 Main Feature (Main_fe) } \\
\hline 15. Robot worked steadily (continuously for a long time). & & & & & 0.81 & \\
\hline 16. Robot was easy to work with. & & & & & 0.83 & \\
\hline 17. Robot was safe and not physically dangerous to children. & & & & & 0.80 & \\
\hline 18. Robot was patient with children. & & & & & 0.81 & \\
\hline \multicolumn{7}{|l|}{ Factor 6 Content } \\
\hline 19. Robot was used as a teaching aid in foreign language learning. & & & & & & 0.76 \\
\hline 20. Robot was used as a teaching aid in science learning. & & & & & & 0.76 \\
\hline 21. Robot was used as a teaching aid in technology learning. & & & & & & 0.79 \\
\hline
\end{tabular}




\section{4-8- Prototype Development}

The results from confirmatory factor analysis (CFA) showed that the friendliest robot shape is likely to be an animal toy or cartoon, which should be friendly, interesting, and respond to learners. Robots interested learners to present and respond to its facial expressions. Aspects influencing the design of the educational robots included attractiveness, intractability, strength, compactness, portability, and cost. In this study, an educational robot prototype called TARAL (Teaching Assistant Robot as Active Learning) was created from the results of confirmatory factor analysis (CFA), which was designed for the specifications of the gamification robot to be compact, portable, and suitably shaped for primary school students [24]. In addition, the robot was required to be able to speak and make sounds to stimulate learners during teaching and learning activities. Furthermore, research and evaluation was required to test and evaluate the robot using qualified tools. The gamification robot was developed from the gamification theory. Thus, the external shape was designed to be a light, portable toy capable of communicating with learners through eye color (grey, blue, green, violet and pink) to show the learner's progress. It also had a loudspeaker to greet learners with expressions such as "Let's play a game", "I am hungry", "Excellent", and "Good job" to enhance engagement between the learners and robot (see Figure 4).

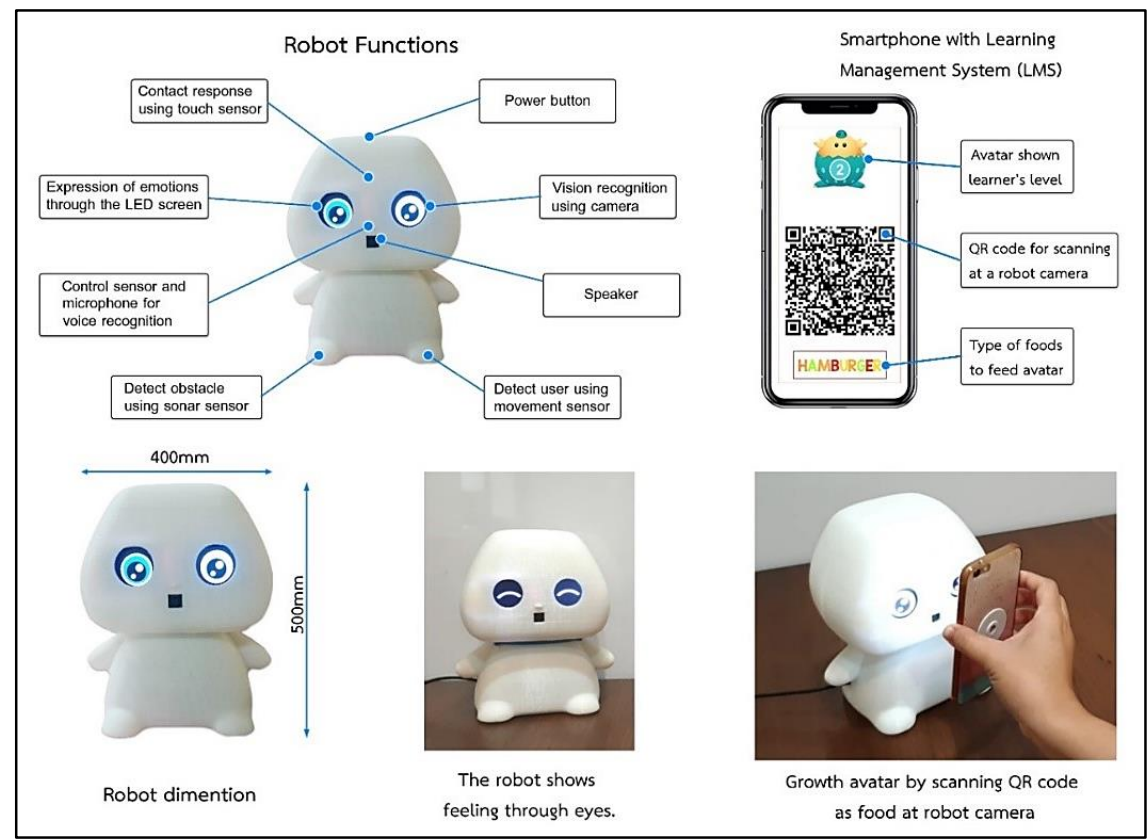

Figure 4. Overview of the TARAL Robot's hardware structure

The robot was developed from a Raspberry Pi 3 Model B board running on Python. A multi-thread working interface with an LCD screen was used to show the robot's eyes. It was connected to a loudspeaker for the robot's voice, and had a camera to evaluate learners' QR codes. Furthermore, the body of the robot was constructed using a 3D printer (see Figure 5).
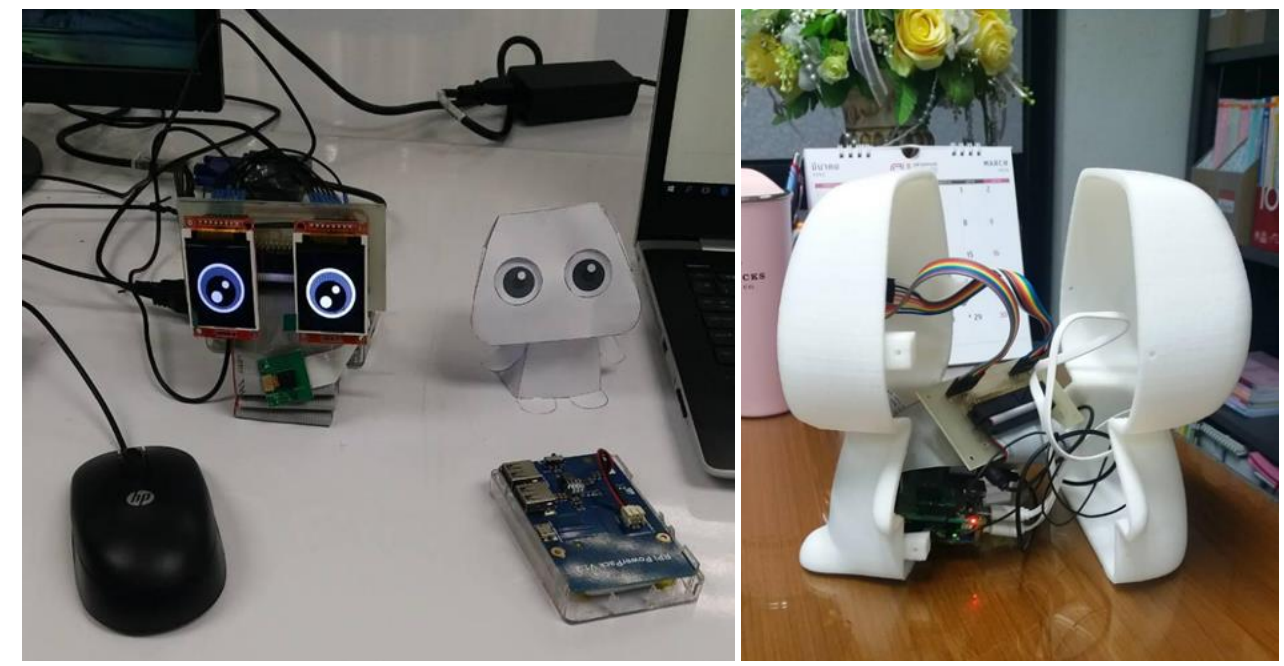

Figure 5. Internal structure of the TARAL Robot 
The gamification robot was linked with a Learning Management System (LMS) (Figure 6) using an opensource model as the main system. For instance, the course content of the LMS system and developed plugin system acted as the supplementary system of function. The level-up system was developed to generate QR codes so that the learner could scan to interface with the robot [27].
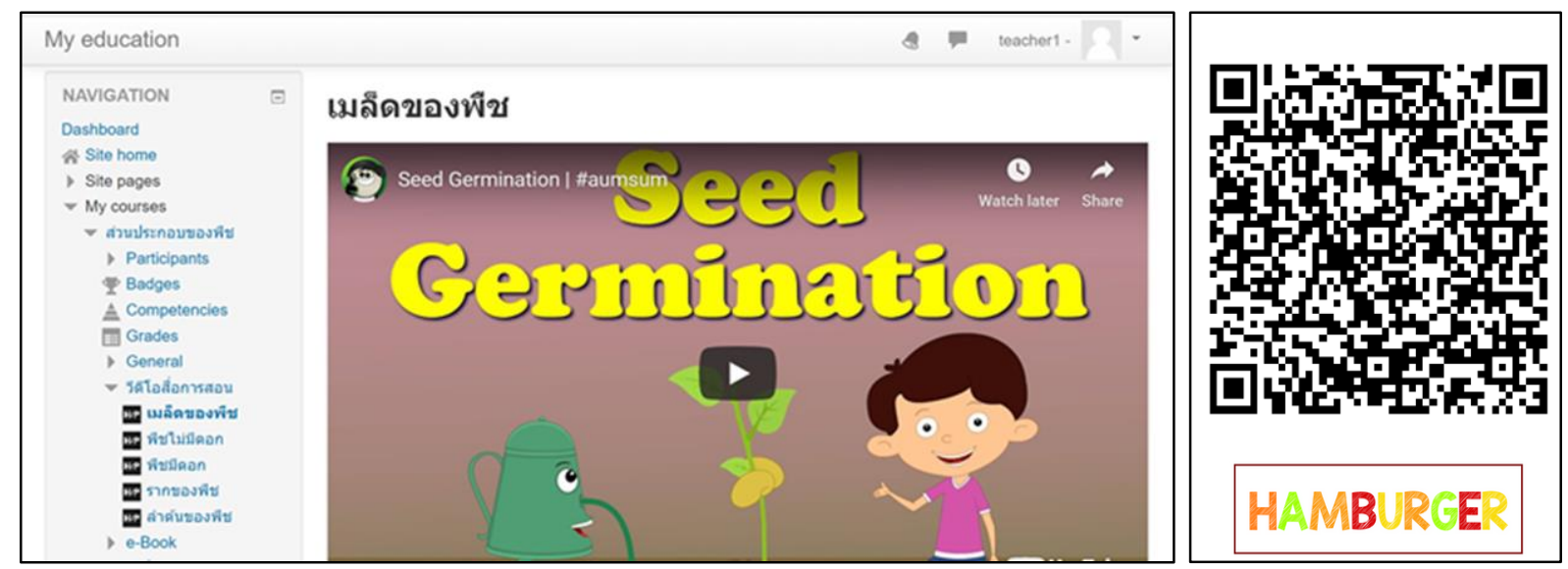

Figure 6. Learning Management System (LMS)

\section{4-9- Prototype Testing}

The teaching and learning process started from students accessing the LMS that used a module system separated into two parts. First, instructors can add any subject material onto the system through various channels (VDO, E-Book, or URL). Furthermore, the instructors could evaluate students' learning by creating tests for them to complete, such as Subjective Tests and Objective Tests. Second, learners could study five lessons given by the instructor. In Prathomsuksa $5\left(5^{\text {th }}\right.$ Grade), the students learned about plants in the science group, which comprised seeds, non-flowering plants, flowering plants, roots, and plant structures. The student learning content was divided into five subject levels so the teacher could set the content priority and students could select their own avatars. After that, the avatars had to be raised by taking a quiz.

The robot was tested for 10 hours at a primary school, with 20 students participating in focus groups. All the students did a pre-test, middle test, and post-test. The quiz included pre-learning and post-learning skills with 4 choices, 5 topics, and 10 questions for each topic for a total of 50 questions. The quiz also included an exercise with five topics that had 10 questions each for a total of 50 questions. The researcher used t-test statistics for data analysis and found that the average learner score with the gamification robot and mobile application had higher post-test thinking skill scores $(\bar{\chi}=$ $35.70, \mathrm{SD}=10.14)$ than the pre-test scores $(\bar{\chi}=19.50, \mathrm{SD}=7.10)) \mathrm{Sig}=0.000<0.05)$. It was found that the average score after learning with the gamification robot with the mobile application was higher for post-learning engagement $(\bar{\chi}=$ $172.55, \mathrm{SD}=20.27)$ than the score for pre-learning engagement $(\bar{\chi}=110.60, \mathrm{SD}=25.14)(\mathrm{Sig}=0.000<0.05)$.

\section{5- Discussion}

Technology plays an important role in the classroom, and education robots can interact with learners' feedback joyfully and improve student engagement with lessons. In this study, developed education robots using the results from confirmatory factor analysis showed improved learning. The factor analysis showed the weight separated into three groups (Table 4): 1) over $0.85 ; 2$ ) between $0.85-0.5$; and 3) under 0.5 . The characteristics and feedback of the teachers and students used robot prototype of each group are described as follows: The first group characteristics were related to teaching, while the second group was learning and teaching development and activities, and the third group was the robot specifications. For the first group, the teaching method weight was the highest at 1.06 (the highest effective dimension). The learning and teaching development and activities in which learners could learn anywhere at any time, and where many learners could learn simultaneously as the robots stayed with each learner [48]. The feedback from learners showed that the robot could be taken anyway thanks to its low weight, and it could react, speak, be fed, and respond with either a voice or song. The teaching method by an academic computer game involving both exercises and skill practice comprised the objectives, rules, competition, challenge, imagination, entertainment, and control. The instructor could evaluate the learners in real time by engineering analysis data, i.e. by fixing start times and enabling quiz scores to be analyzed quickly, while predicted future learning results would adjust adaptive questions [47].

The second group involved learning and teaching development and activities. The feedback from the learners showed that emotional development and engagement were used so that the robot could react to the learners enthusiastically, in an exciting way, and ensure that the learners enjoyed the activities by engaging with it and attempting to answer questions as correctly as possible [49]. Learners received real items form the instructor, such as hats, socks, scarfs, badges, and so on, which were the same items they received from the computer game shown on the screen in order to 
stimulate and motivate the learner to learn. Most learners commented that the school should use robots. From the interviews, most of the instructors who used the robot commented that the learners were more interested in learning and attempted to level up quickly [50]. Sometimes, instructors warned their learners to study the pre-test lesson in advance, but the teachers had to remind them to study the lessons ahead of the e-learning system. From observations, it was found that the learners were interested in learning from the robot's reactions robot at a satisfactory level, with an average pilot period of 10-15 hours. The instructors at each school actively assisted in the experiment, which was also well supported by the schools [26]. Furthermore, the teaching and learning arrangement depended on the readiness of learners, including their responsibility and discipline, while the challenge of learning affected the success of the test [18, 51].

For the third group, the robot specifications, it was found that the main features (Main_fe) had a weight of 0.41 . The feedback on robot specifications included it being small, easy to carry, cute, and light. The specifications were suitable for learners [52]. The interactive robot was based on the game concept and was a tool for teaching and a learning aid, while it could also be used for competition, support, challenge, and engagement, which complied with the idea to link the game to mobile application software and comply with robot technology standards [53].

\section{6- Conclusion}

The objective of this research was to determine how teachers envision integrating educational robots into learning. Prototype testing found that the education robot designed from the confirmatory factor analysis (CFA) results served to improve the focus group learners' behavior and support the instructors during the learning process. As for the first research question, we concluded that teachers envision integrating educational robots into learning six major factors examined as (1) Social interaction, (2) Cognitive function, (3) Teaching method, (4) Learner characteristics, (5) Main features, and (6) Content presented a good fit. The research showed that the teaching method and teaching development and activities are most important and needed to succeed in education robots learning. Previous studies have shown that education robots need to be supported by instructional design. Education robots could be integrated into a pedagogical strategy for the benefits of students' learning and development. The connection between activities would create more effective learning. Regarding the second research question, feedback from this study indicates several of the successes and challenges that teachers may encounter when integrating robotics into their teaching activities. In terms of success, students were very interested in the robot; learners were interested in the robot because of the robot's speech, voice, and eye color changes when they levelled up. The impact of the robot uses engagement for students' learning. Integrated LMS with robots was shown to be a challenge. Some students had a short attention span, while some teachers lacked experience and confidence with robots integrated with LMS. The biggest challenge for teachers and students is to be more dedicated outside of the classroom. This will reveal possible opportunities for teachers to use education robots to improve student learning and engagement. Future researchers should expand their studies to look into the opportunities and challenges that teachers and school administrators face regularly in the classroom.

\section{7- Declarations}

\section{7-1-Author Contributions}

Conceptualization, methodology, software, validation, formal analysis, investigation, resources, data curation, K.P., N.S., K.P. and N.S.; writing - original draft preparation, writing - review and editing, visualization, K.P. and N.S.; supervision N.S.; project administration, N.S.; funding acquisition, K.P. and N.S. All authors have read and agreed to the published version of the manuscript.

\section{7-2-Data Availability Statement}

The data presented in this study are available on request from the corresponding author.

\section{7-3- Funding}

This research project is supported by the Second Century Fund (C2F), Chulalongkorn University, Thailand.

\section{7-4- Conflicts of Interest}

The authors declare that there is no conflict of interests regarding the publication of this manuscript. In addition, the ethical issues, including plagiarism, informed consent, misconduct, data fabrication and/or falsification, double publication and/or submission, and redundancies have been completely observed by the authors.

\section{8- References}

[1] UNICEF (United Nations Children's Fund). Children in a Digital World. New York, USA: UNICEF Division of Communication, (2017)

[2] Beran, Tanya N., Alejandro Ramirez-Serrano, Roman Kuzyk, Meghann Fior, and Sarah Nugent. "Understanding How Children Understand Robots: Perceived Animism in Child-robot Interaction.” International Journal of Human-Computer Studies 69, no. 7-8 (July 2011): 539-550. doi:10.1016/j.ijhcs.2011.04.003. 
[3] Ahmad, Muneeb Imtiaz, Omar Mubin, and Joanne Orlando. "Adaptive Social Robot for Sustaining Social Engagement during Long-Term Children-Robot Interaction.” International Journal of Human-Computer Interaction 33, no. 12 (March 3, 2017): 943962. doi:10.1080/10447318.2017.1300750.

[4] Armesto, Leopoldo, Pedro Fuentes-Durá, and David Perry. "Low-Cost Printable Robots in Education.” Journal of Intelligent \& Robotic Systems 81, no. 1 (February 25, 2015): 5-24. doi:10.1007/s10846-015-0199-x.

[5] Chen, Nian-Shing, Benazir Quadir, and Daniel C. Teng. "A Novel Approach of Learning English with Robot for Elementary School Students.” Lecture Notes in Computer Science (2011): 309-316. doi:10.1007/978-3-642-23456-9_58.

[6] Wei, Chun-Wang, I. Chun Hung, Ling Lee, and Nian-Shing Chen. "A Joyful Classroom Learning System with Robot Learning Companion for Children to Learn Mathematics Multiplication." Turkish Online Journal of Educational Technology, 10 (2011).

[7] Jones, Aidan, and Ginevra Castellano. "Adaptive Robotic Tutors That Support Self-Regulated Learning: A Longer-Term Investigation with Primary School Children." International Journal of Social Robotics 10, no. 3 (2018): 357-70. doi:10.1007/s12369-017-0458-z.

[8] Chang, Chih-Wei, Jih-Hsien Lee, Po-Yao Chao, Chin-Yeh Wang, and Gwo-Dong Chen. "Exploring the Possibility of Using Humanoid Robots as Instructional Tools for Teaching a Second Language in Primary School." Educational Technology \& Society 13 (2010): 13-24.

[9] Andruseac, Gabriela Gladiola, Raluca Ioana Adochiei, Alexandru Pasarica, Felix-Constantin Adochiei, Calin Corciova, and Hariton Costin. "Training Program for Dyslexic Children Using Educational Robotics." 2015 E-Health and Bioengineering Conference (EHB) (November 2015). doi:10.1109/ehb.2015.7391547.

[10] Egido-García, Verónica, David Estévez, Ana Corrales-Paredes, María-José Terrón-López, and Paloma-Julia Velasco-Quintana. "Integration of a Social Robot in a Pedagogical and Logopedic Intervention with Children: A Case Study." Sensors 20, no. 22 (2020): 6483. https://www.mdpi.com/1424-8220/20/22/6483

[11] Galvez Trigo, Maria Jose, Penelope Jane Standen, and Sue Valerie Gray Cobb. "Robots in Special Education: Reasons for Low Uptake." Journal of Enabling Technologies 13, no. 2 (2019): 59-69. doi:10.1108/JET-12-2018-0070.

[12] McNeill, M. D. J., D. K. Charles, J. W. Burke, J. H. Crosbie, and S. M. McDonough. "Evaluating User Experiences in Rehabilitation Games." Journal of Assistive Technologies 6, no. 3 (2012): 173-81. doi:10.1108/17549451211261290.

[13] Benitti, Fabiane Barreto Vavassori. "Exploring the Educational Potential of Robotics in Schools: A Systematic Review." Computers \& Education 58, no. 3 (April 2012): 978-988. doi:10.1016/j.compedu.2011.10.006.

[14] Johnson, Larry, Samantha Adams Becker, Michele Cummins, Victoria Estrada, Alex Freeman, and Courtney Hall. Nmc Horizon Report: 2016 Higher Education Edition. The New Media Consortium (Austin, Texas: 2016).

[15] Kazimoglu, Cagin, Mary Kiernan, Liz Bacon, and Lachlan Mackinnon. "A Serious Game for Developing Computational Thinking and Learning Introductory Computer Programming." Procedia - Social and Behavioral Sciences 47 (2012): $1991-99$. doi:10.1016/j.sbspro. 2012.06.938.

[16] Ortiz, A. M. "Examining Students' Proportional Reasoning Strategy Levels as Evidence of the Impact of an Integrated Lego Robotics and Mathematics Learning Experience." Journal of Technology Education 26 (2015): 46-69. doi:10.21061/jte.v26i2.a.3.

[17] Tlili, Ahmed, Vivien Lin, Nian-Shing Chen, Ronghuai Huang, and Dr Kinshuk. "A Systematic Review on Robot-Assisted Special Education from the Activity Theory Perspective." Educational Technology \& Society 23 (2020): 1176-3647.

[18] Alamo, Judit, Eduardo Quevedo, Alejandro Santana Coll, Samuel Ortega, Himar Fabelo, Gustavo M. Callico, and Alberto Zapatera. "Sustainable Educational Robotics. Contingency Plan during Lockdown in Primary School." Sustainability 13, no. 15 (2021): 8388 .

[19] Fridin, Marina. "Kindergarten Social Assistive Robot: First Meeting and Ethical Issues." Computers in Human Behavior 30 (2014): 262-72. doi:10.1016/j.chb.2013.09.005.

[20] Keren, Guy, and Marina Fridin. "Kindergarten Social Assistive Robot (Kindsar) for Children's Geometric Thinking and Metacognitive Development in Preschool Education: A Pilot Study." Computers in Human Behavior 35 (2014): 400-12. doi:10.1016/j.chb.2014.03.009.

[21] Westlund, Jacqueline Kory, and Cynthia Breazeal. "Storytelling with Robots: Learning Companions for Preschool Children's Language Development." The 23rd IEEE International Symposium on Robot and Human Interactive Communication (2014): 643-48.

[22] Moriguchi, Yusuke, Takayuki Kanda, Hiroshi Ishiguro, Yohko Shimada, and Shoji Itakura. "Can Young Children Learn Words from a Robot?". Interaction Studies 12 (2011): 107-18. doi:10.1075/is.12.1.04 mor.

[23] Chersi, Fabian. "Learning through Imitation: A Biological Approach to Robotics." IEEE Transactions on Autonomous Mental Development 4 (2012): 204-14. doi:10.1109/TAMD.2012.2200250. 
[24] Nascimento, Lucas Moura do, Davi Souto Neri, Thiago do Nascimento Ferreira, Francinaldo de Almeida Pereira, Erika Akemi Yanaguibashi Albuquerque, Luiz Marcos Garcia Gonçalves, and Sarah Thomaz de Lima Sá. "Sbotics - Gamified Framework for Educational Robotics." Journal of Intelligent \& Robotic Systems 102, no. 1 (2021): 17. doi:10.1007/s10846-021-01364-8.

[25] Leite, Iolanda, Carlos Martinho, and Ana Paiva. "Social Robots for Long-Term Interaction: A Survey." International Journal of Social Robotics 5, no. 2 (2013): 291-308. doi:10.1007/s12369-013-0178-y.

[26] Tang, Anne L. L., Vincent Wing Sun Tung, and Tiffany O. Cheng. "Dual Roles of Educational Robotics in Management Education: Pedagogical Means and Learning Outcomes." Education and Information Technologies 25, no. 2 (2020): 1271-83. doi:10.1007/s10639-019-10015-3.

[27] Jung, Sung, and Eun-sok Won. "Systematic Review of Research Trends in Robotics Education for Young Children." Sustainability 10 (2018): 905. doi:10.3390/su10040905.

[28] Haywood, H. Carl, and Carol S. Lidz. Dynamic Assessment in Practice: Clinical and Educational Applications. Cambridge: Cambridge University Press, (2006). doi:10.1017/CBO9780511607516.

[29] Eklundh, Kerstin, Anders Green, and Helge Hüttenrauch. "Social and Collaborative Aspects of Interaction with a Service Robot." Robotics and Autonomous Systems 42 (2003): 223-34. doi:10.1016/S0921-8890(02)00377-9.

[30] Yanış, Hilal, and Nejla Yürük. "Development, Validity, and Reliability of an Educational Robotics Based Technological Pedagogical Content Knowledge Self-Efficacy Scale." Journal of Research on Technology in Education 53, no. 4 (2021): 375403. doi:10.1080/15391523.2020.1784065.

[31] Altin, Heilo and Margus Pedaste. "Learning Approaches to Applying Robotics in Science Education." Journal of Baltic Science Education 12 (2013).

[32] Cacco, L.; Moro, M. When a Bee meets a Sunflower. In Proceedings of the 4th International Workshop Teaching Robotics, Teaching with Robotics \& 5th International Conference Robotics in Education, Padova, Italy, 18 July 2014; pp. 68-75

[33] McLurkin, J, J Rykowski, M John, Q Kaseman, and A J. Lynch. "Using Multi-Robot Systems for Engineering Education: Teaching and Outreach with Large Numbers of an Advanced, Low-Cost Robot." IEEE Transactions on Education 56, no. 1 (2013): 24-33.

[34] Nag, Sreeja, Jacob G. Katz, and Alvar Saenz-Otero. "Collaborative Gaming and Competition for Cs-Stem Education Using Spheres Zero Robotics." Acta Astronautica 83 (2013): 145-74. doi:10.1016/j.actaastro.2012.09.006.

[35] Alimisis, Dimitris. "Robotics in Education \& Education in Robotics: Shifting Focus from Technology to Pedagogy." (2012).

[36] Heerink, Marcel, Ben Kröse, Vanessa Evers, and Bob Wielinga. "Assessing Acceptance of Assistive Social Agent Technology By older Adults: The Almere Model." International Journal of Social Robotics 2, no. 4 (2010): 361-75. doi:10.1007/s12369010-0068-5.

[37] Altun Yalcin, Sema, Sakip Kahraman, and Zeynel Abidin Yilmaz. "Development and Validation of Robotic Coding Attitude Scale." International Journal of Education in Mathematics, Science and Technology 8, no. 4 (2020): 342. doi:10.46328/ijemst.v8i4.924.

[38] Cabibihan, John-John, Hifza Javed, Marcelo Jr, and Sharifah Aljunied. "Why Robots? A Survey on the Roles and Benefits of Social Robots in the Therapy of Children with Autism." International Journal of Social Robotics 5 (2013). doi:10.1007/s12369-013-0202-2.

[39] Toh, Lai, Albert Causo, Pei-Wen Tzuo, I. Ming Chen, and Song Yeo. "A Review on the Use of Robots in Education and Young Children." Educational Technology \& Society 19 (2016): 148-63.

[40] Kahn, P. H., Jr., T. Kanda, H. Ishiguro, N. G. Freier, R. L. Severson, B. T. Gill, J. H. Ruckert, and S. Shen. "'Robovie, You'll Have to Go into the Closet Now": Children's Social and Moral Relationships with a Humanoid Robot." Dev Psychol 48, no. 2 (Mar 2012): 303-14. doi:10.1037/a0027033.

[41] Shimada, Michihiro, Takayuki Kanda, and Satoshi Koizumi. "How Can a Social Robot Facilitate Children's Collaboration?" Lecture Notes in Computer Science (2012): 98-107. doi:10.1007/978-3-642-34103-8_10.

[42] Mubin, O., Stevens, C. J., Shahid, S., Mahmud, A. A., \& Dong, J.-J. (2013). A Review of the Applicability of Robots In Education. Technology for Education and Learning, 1(1). doi:10.2316/journal.209.2013.1.209-0015.

[43] Hong, Jon-Chao, Kuang-Chao Yu, and Mei-Y. Chen. "Collaborative Learning in Technological Project Design.” International Journal of Technology and Design Education 21, no. 3 (May 22, 2010): 335-347. doi:10.1007/s10798-010-9123-7.

[44] Barker, Bradley S., and John Ansorge. "Robotics as Means to Increase Achievement Scores in an Informal Learning Environment." Journal of Research on Technology in Education 39, no. 3 (March 2007): 229-243. doi:10.1080/15391523.2007.10782481. 
[45] Kazakoff, Elizabeth R., Amanda Sullivan, and Marina U. Bers. "The Effect of a Classroom-Based Intensive Robotics and Programming Workshop on Sequencing Ability in Early Childhood." Early Childhood Education Journal 41, no. 4 (2013): $245-$ 55. doi:10.1007/s10643-012-0554-5.

[46] Breazeal, Cynthia, Kerstin Dautenhahn, and Takayuki Kanda. "Social Robotics.” Springer Handbook of Robotics (2016): 19351972. doi:10.1007/978-3-319-32552-1_72.

[47] Gubenko, Alla, Christiane Kirsch, Jan Nicola Smilek, Todd Lubart, and Claude Houssemand. "Educational Robotics and Robot Creativity: An Interdisciplinary Dialogue." [In English]. Hypothesis and Theory. Frontiers in Robotics and AI 8, no. 178 (June 2021). doi:10.3389/frobt.2021.662030.

[48] Kory Westlund, Jacqueline M., Sooyeon Jeong, Hae W. Park, Samuel Ronfard, Aradhana Adhikari, Paul L. Harris, David DeSteno, and Cynthia L. Breazeal. "Flat Vs. Expressive Storytelling: Young Children's Learning and Retention of a Social Robot's Narrative." (In English). Original Research. Frontiers in Human Neuroscience 11, no. 295 (June 2017). doi:10.3389/fnhum.2017.00295.

[49] Cooney, Martin, and Wolfgang Leister. "Using the Engagement Profile to Design an Engaging Robotic Teaching Assistant for Students." Robotics 8 (2019): 1-26. doi:10.3390/robotics8010021.

[50] Malik, Norjasween Abdul, Fazah Akhtar Hanapiah, Rabiatul Adawiah Abdul Rahman, and Hanafiah Yussof. "Emergence of Socially Assistive Robotics in Rehabilitation for Children with Cerebral Palsy: A Review." International Journal of Advanced Robotic Systems 13, no. 3 (2016): 135. doi:10.5772/64163.

[51] Xefteris, S. "Developing Steam Educational Scenarios in Pedagogical Studies Using Robotics: An Undergraduate Course for Elementary School Teachers." Engineering, Technology \&amp; Applied Science Research 11, no. 4 (2021): 7358-62. doi:10.48084/etasr.4249.

[52] Sim, Doreen Ying Ying, and Chu Kiong Loo. "Extensive Assessment and Evaluation Methodologies on Assistive Social Robots for Modelling Human-robot Interaction - A Review.” Information Sciences 301 (April 2015): $305-344$. doi:10.1016/j.ins.2014.12.017.

[53] Van den Heuvel, Renée J. F., Monique A. S. Lexis, Gert Jan Gelderblom, Rianne M. L. Jansens, and Luc P. de Witte. "Robots and ICT to Support Play in Children with Severe Physical Disabilities: a Systematic Review." Disability and Rehabilitation: Assistive Technology 11, no. 2 (September 2, 2015): 103-116. doi:10.3109/17483107.2015.1079268. 